\title{
Metformin Use Is Associated With Longer Progression-Free Survival of Patients With Diabetes and Pancreatic Neuroendocrine Tumors Receiving Everolimus and/or Somatostatin Analogues
}

Sara Pusceddu, ${ }^{1}$ Claudio Vernieri, ${ }^{1,2}$ Massimo Di Maio, ${ }^{3}$ Riccardo Marconcini, ${ }^{4}$ Francesca Spada, ${ }^{5}$ Sara Massironi, ${ }^{6}$ Toni Ibrahim,, ${ }^{7}$ Maria Pia Brizzi, ${ }^{8}$ Davide Campana, ${ }^{9}$ Antongiulio Faggiano, ${ }^{10}$ Dario Giuffrida, ${ }^{11}$ Maria Rinzivillo, ${ }^{12}$ Sara Cingarlini, ${ }^{13}$ Francesca Aroldi, ${ }^{14}$ Lorenzo Antonuzzo, ${ }^{15}$ Rossana Berardi, ${ }^{16}$ Laura Catena, ${ }^{17}$ Chiara De Divitiis, ${ }^{18}$ Paola Ermacora, ${ }^{19}$ Vittorio Perfetti, ${ }^{20}$ Annalisa Fontana, ${ }^{21}$ Paola Razzore, ${ }^{22}$ Carlo Carnaghi, ${ }^{23}$ Maria Vittoria Davì, ${ }^{24}$ Carolina Cauchi, ${ }^{25}$ Marilina Duro, ${ }^{26}$ Sergio Ricci, ${ }^{4}$ Nicola Fazio, ${ }^{5}$ Federica Cavalcoli, ${ }^{6}$ Alberto Bongiovanni, ${ }^{7}$ Anna La Salvia, ${ }^{8}$ Nicole Brighi, ${ }^{9}$ Annamaria Colao, ${ }^{27}$ Ivana Puliafito, ${ }^{11}$ Francesco Panzuto, ${ }^{12}$ Silvia Ortolani, ${ }^{13}$ Alberto Zaniboni, ${ }^{14}$ Francesco Di Costanzo, ${ }^{15}$ Mariangela Torniai, ${ }^{16}$ Emilio Bajetta, ${ }^{17}$ Salvatore Tafuto, ${ }^{18}$ Silvio Ken Garattini, ${ }^{19}$ Daniela Femia, ${ }^{1}$ Natalie Prinzi, ${ }^{1}$ Laura Concas, ${ }^{1}$ Giuseppe Lo Russo, ${ }^{1,28}$ Massimo Milione, ${ }^{1}$ Luca Giacomelli, ${ }^{29}$ Roberto Buzzoni, ${ }^{1}$ Gianfranco Delle Fave, ${ }^{12}$ Vincenzo Mazzaferro, ${ }^{1,30}$ and Filippo de Braud ${ }^{1,30}$

${ }^{1}$ Fondazione IRCCS Istituto Nazionale dei Tumori di Milano, ENETS Center of Excellence; ${ }^{2}$ Fondazione Istituto FIRC di Oncologia Molecolare (IFOM), Milan; ${ }^{3}$ Dipartimento di Oncologia, Università degli Studi di Torino, A. O. Ordine Mauriziano, Turin; ${ }^{4}$ Dipartimento di Oncologia, Santa Chiara Hospital, Azienda Ospedaliero-Universitaria Pisana, Pisa; ${ }^{5}$ IEO - Istituto Europeo di Oncologia, ENETS Center of Excellence; ' ${ }^{6}$ Fondazione IRCCS Ca' Granda, Ospedale Maggiore Policlinico, Università degli Studi di Milano, Milan; ${ }^{7}$ Centro di Osteoncologia e Tumori Rari, Istituto Scientifico Romagnolo per lo Studio e la Cura dei Tumori (IRST) IRCCS, Meldola; ${ }^{8}$ Azienda Ospedaliera Universitaria San Luigi Gonzaga, Orbassano; ${ }^{9}$ Policlinico Sant'Orsola Malpighi, Bologna; ${ }^{10}$ Unità di chirurgia tiroidea e paratiroidea, Istituto Nazionale per lo studio e la cura dei tumori "Fondazione G. Pascale" - IRCCS, Naples; ${ }^{11}$ IOM- Istituto Oncologico del Mediterraneo, Catania; ${ }^{12}$ Azienda Ospedaliera Universitaria Sant'Andrea, ENETS Center of Excellence, Rome; ${ }^{13}$ Azienda Ospedaliera Universitaria, Verona; ${ }^{14}$ Fondazione Poliambulanza, Brescia; ${ }^{15}$ A. O. U. Careggi, Firenze; ${ }^{16}$ Azienda Ospedaliero Universitaria Ospedali Riuniti, Ancona; ${ }^{17}$ Policlinico di Monza, Monza; ${ }^{18}$ IRCCS Fondazione Pascale, ENETS Center of Excellence, Naples; ${ }^{19}$ Azienda Ospedaliero Universitaria Santa Maria della Misericordia, Udine; ${ }^{20}$ Fondazione IRCCS Policlinico San Matteo, SC oncologia, Pavia; ${ }^{21}$ Policlinico di Modena; ${ }^{22}$ Unit of Endocrinology, Ospedale Mauriziano, Torino; ${ }^{23}$ Istituto Clinico Humanitas, Rozzano, ENETS Center of Excellence; ${ }^{24}$ Ospedale Policlinico Borgo Roma, Verona; ${ }^{25}$ Ospedale S Croce e Carle, Cuneo; ${ }^{26}$ Ospedale Valduce Como;

${ }^{27}$ Endocrinology Section, Department of Clinical Medicine and Surgery, "Federico II" University of Naples; ${ }^{28}$ Medical-Surgical Science and Traslational Medicine Departement, Sapienza University, Rome; ${ }^{29}$ Department of Surgical Sciences and Integrated Diagnostics, University of Genoa; and ${ }^{30}$ Universita' degli Studi di Milano, Milan, Italy
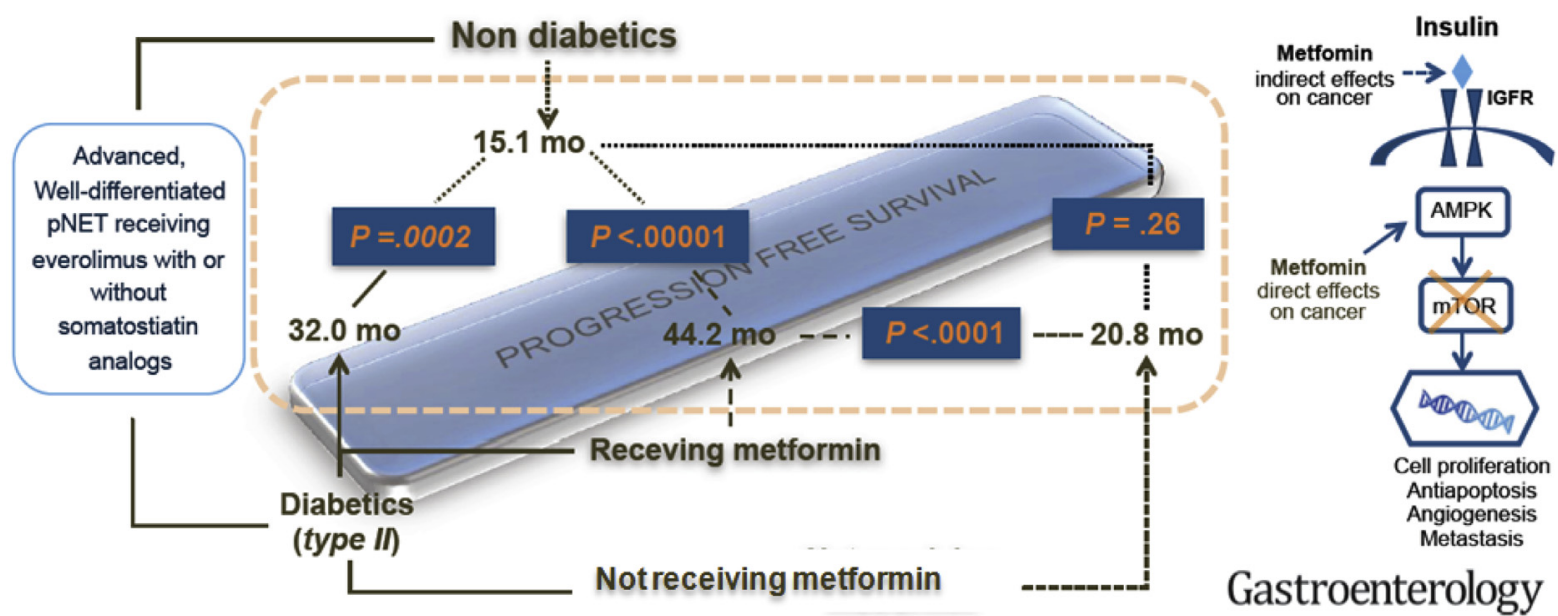

Gastroenterology 
BACKGROUND \& AIMS: Metformin seems to have anticancer effects. However, it is not clear whether use of glycemia and metformin affect outcomes of patients with advanced pancreatic neuroendocrine tumors (pNETs). We investigated the association between glycemia and progression-free survival (PFS) of patients with pNETs treated with everolimus and/or somatostatin analogues, as well as the association between metformin use and PFS time. METHODS: We performed a retrospective analysis of 445 patients with advanced pNET treated at 24 medical centers in Italy from 1999 through 2015. Data on levels of glycemia were collected at time of diagnosis of pNET, before treatment initiation, and during treatment with everolimus (with or without somatostatin analogues), octreotide, or lanreotide. Diabetes was defined as prior or current use of glycemia control medication and/or fasting plasma glucose level $\geq 126 \mathrm{mg} / \mathrm{dL}$, hemoglobin $\mathrm{A} 1 \mathrm{c} \geq$ $6.5 \%$ ( $48 \mathrm{mmol} / \mathrm{L}$ ), or a random sample of plasma glucose $\geq$ $200 \mathrm{mg} / \mathrm{dL}$ (11.1 mmol/L), with reported classic symptoms of hyperglycemia or hyperglycemic crisis. Patients were assigned to groups based on diagnosis of diabetes before or during antitumor therapy. PFS was compared between patients with vs without diabetes. Among patients with diabetes, the association between metformin use and PFS was assessed. We performed sensitivity and landmark analyses to exclude patients who developed diabetes while receiving cancer treatment and to exclude a potential immortal time bias related to metformin intake. RESULTS: PFS was significantly longer in patients with diabetes (median, 32.0 months) than without diabetes (median, 15.1 months) (hazard ratio for patients with vs without diabetes, $0.63 ; 95 \%$ confidence interval, $0.50-0.80$; $P=.0002$ ). PFS of patients treated with metformin was significantly longer (median PFS, 44.2 months) than for patients without diabetes (hazard ratio for survival of patients with diabetes receiving metformin vs without diabetes, 0.45 ; 95\% confidence interval, $0.32-0.62 ; P<.00001$ ) and longer than for patients with diabetes receiving other treatments (median PFS, 20.8 months; hazard ratio, 0.49; 95\% confidence interval, 0.34-0.69; $P<.0001$ ). In multivariable analysis, adjusted for other factors associated with outcomes, metformin was associated with longer PFS but level of glycemia was not. Metformin was associated with increased PFS of patients receiving somatostatin analogues and in those receiving everolimus, with or without somatostatin analogues. Sensitivity and landmark analyses produced similar results. CONCLUSIONS: In a retrospective study of patients with pNETs, we found a significant association between metformin use and longer PFS.

Keywords: Chemoprevention; Drug; Insulin Resistance; Pancreas.

$\mathrm{T}$ he incidence of pancreatic neuroendocrine tumors (pNETs) is increasing, and about $50 \%$ of patients present with advanced disease at diagnosis., ${ }^{1,2}$ Although surgery is the only curative treatment for limited-stage disease, $^{3}$ the 5 -year survival rate is $32 \%$ for patients with advanced pNETs. ${ }^{4}$ Therapeutic options include liverdirected therapies, chemotherapy, somatostatin analogues (SSAs), the mechanistic target of rapamycin (mTOR)

WHAT YOU NEED TO KNOW
BACKGROUND AND CONTEXT
Metformin seems to have anti-cancer effects. However, it
is not clear whether use of glycemia and metformin affect
outcomes of patients with advanced pancreatic
neuroendocrine tumors (pNETs).
NEW FINDINGS
This study suggests that a significant association
between metformin use and longer PFS exists in
patients with pNETs.
LIMITATIONS
Retrospective analysis; non standardized administration
schedule for metformin.
IMPACT
Metformin could have some antitumor effects in the
treatment of patients with advanced pNETs. On these
bases, two phase II studies are currently ongoing to
further investigate these preliminary findings.

inhibitor everolimus, the multikinase inhibitor sunitinib, and peptide receptor radiotherapy. ${ }^{5-8}$

Although type 2 diabetes mellitus (T2DM) has emerged as a risk factor for the development of pNETs in some studies, ${ }^{9,10}$ its prognostic role in patients with advanced disease remains unexplored. Indeed, chronic elevation of glycemia may increase the risk of cancer by stimulating tumor anabolism, compensatory hyperinsulinemia, and cell proliferation through stimulation of the mTOR and mitogen-activated protein kinase pathways. ${ }^{11-13}$ In many tumors, hyperglycemia and diabetes are associated with higher aggressiveness. In addition, DM is frequently present at diagnosis in advanced pNETs as a consequence of pancreatic involvement by the tumor; rarely, paraneoplastic syndromes (glucagonomas) ${ }^{14}$; or, more often, surgical $^{15}$ (partial or total pancreatectomy) or medical (SSAs or everolimus) treatments. ${ }^{5,8,16-18}$ In particular, everolimus induces insulin resistance and hyperinsulinemia through the combination of impaired insulin secretion and insulin resistance, whereas SSAs inhibit insulin secretion because of an induced decrease in pancreatic $\beta$-cell function. ${ }^{17,18}$

Metformin, the most widely used drug in the treatment of T2DM, is emerging as a potentially active agent in cancer chemoprevention and treatment. ${ }^{19-23}$ Its proposed antitumor mechanisms include the reduction of blood glucose, insulin, and IGF-1 levels as well as cell-autonomous

Abbreviations used in this paper: AMPK, adenosine monophosphateactivated kinase; $\mathrm{Cl}$, confidence interval; $\mathrm{HR}$, hazard ratio; mTOR, mechanistic target of rapamycin; OS, overall survival; PFS, progression-free survival; pNET, pancreatic neuroendocrine tumor; SSA, somatostatin analogue; T2DM, type 2 diabetes mellitus.

Most current article

(C) 2018 by the AGA Institute 0016-5085/\$36.00

https://doi.org/10.1053/j.gastro.2018.04.010 
anticancer effects mediated by the inhibition of mitochondrial oxidation, activation of adenosine monophosphateactivated kinase (AMPK), and inhibition of mTOR. ${ }^{20-24}$ By reinforcing mTOR inhibition and preventing activation of the IGF-1 oncogenic axis, metformin could synergize with everolimus and SSAs. ${ }^{25}$ In a previous pilot experience, we investigated the prognosis of 31 patients with pNETs treated with everolimus and octreotide LAR; diabetic patients treated with metformin showed increased PFS compared with nondiabetic individuals and diabetic individuals not taking metformin. ${ }^{25}$

However, to our knowledge, the prognostic role of diabetes and metformin use has never been investigated in large populations of patients with advanced pNETs. We performed the multicenter Pancreatic Retrospective Italian MEtformin-NET (ie, PRIME-NET) study to evaluate the association between glycemic status and outcome, measured in terms of PFS and overall survival (OS), in a large population of patients with advanced pNETs. Here, we present our findings about the associations among glycemic status, metformin use, and PFS. Data on OS is not yet mature because of the low number of deaths occurring to date; it will be presented in a separate final report.

\section{Patients and Methods}

\section{Study Setting}

This was a multicenter, retrospective, independent study of 445 patients with advanced pNETs, treated between 1999 and 2015 at 24 Italian centers. The ethical committee of the coordinating center (Fondazione IRCCS Istituto Tumori Nazionale dei Tumori di Milano, Milan, Italy) approved the study design. All patients signed an informed consent for the use of their personal data for research purposes.

Patients $\geq 18$ years old were eligible if they had unresectable (locally advanced or metastatic), well-differentiated (Ki-67 score $<50 \%$ ) pNET. $^{26}$ Other eligibility criteria were (1) Eastern Cooperative Oncology Group performance status 0-3; (2) evaluation of fasting glycemia and/or glycosylated hemoglobin $(\mathrm{HbA} 1 \mathrm{c})$ at diagnosis, before treatment initiation, and during treatment; and (3) antitumor treatment with everolimus, everolimus plus SSA (octreotide or lanreotide), or SSA alone. Patients were ineligible if they had a poorly differentiated neuroendocrine carcinoma or type 1 diabetes mellitus.

Glycemic status was assessed at diagnosis, before treatment initiation, and during treatment by standard laboratory tests. There were no predefined time points for the assessment of glycemia, except for baseline evaluations.

Diabetic patients were defined on the basis of either a documented diagnosis of T2DM before treatment initiation (basal diabetes) or the occurrence of diabetes during oncological therapy (on-treatment diabetes). We considered as diabetics those patients with a medical history of T2DM; those with previous or current use of antihyperglycemic medication; and, according to international guidelines, those who met 1 of the following criteria: fasting plasma glucose level $\geq 126 \mathrm{mg} /$ $\mathrm{dL}(7.0 \mathrm{mmol} / \mathrm{L}),{ }^{27} \mathrm{HbA} 1 \mathrm{c} \geq 6.5 \%$ (48 mmol/L), or random plasma glucose level $\geq 200 \mathrm{mg} / \mathrm{dL}(11.1 \mathrm{mmol} / \mathrm{L})$ with reported classic symptoms of hyperglycemia or hyperglycemic crisis. Nondiabetics were those subjects who did not meet any of these criteria at any time during the study.

\section{Objectives and Design}

The primary objective of this study was to investigate a possible association between T2DM and PFS (primary endpoint). Secondary objectives were to evaluate whether an association exists between (1) diabetes and OS (secondary endpoint); (2) metformin therapy and clinical outcomes (PFS and OS) in diabetic patients; and (3) diabetes, metformin use, and clinical outcomes (PFS and OS) in patients receiving everolimus and/or SSAs (subgroup analysis).

PFS analysis was first performed in nondiabetic patients and in those with T2DM. Then, T2DM patients were further divided according to their antidiabetic treatment, and PFS was separately analyzed in (1) diabetics taking metformin (alone or combined with other antidiabetic therapies), (2) diabetics taking insulin or eating a modified diet (i.e., not receiving metformin), and (3) nondiabetic patients (Supplementary Figure 1).

\section{Statistical Analysis}

Patients' characteristics were analyzed by descriptive statistics. PFS was defined as time from treatment initiation to disease progression (assessed according to clinical practice at the time of diagnosis), death from any cause, last visit, or loss to follow-up. OS was defined as time from treatment initiation to death from any cause. Risk for disease progression and for overall mortality was compared using the Kaplan-Meier method.

Disease progression was measured according to Response Evaluation Criteria in Solid Tumors (ie, RECIST) criteria $^{28}$ (version 1.1), based on a set of measurable lesions identified at baseline of treatment as target lesions, and-together with other lesions that are denoted as nontarget lesions-followed until disease progression.

Tumor radiologic assessments were performed at diagnosis, before treatment initiation, and during treatment by computed tomography or magnetic resonance imaging. Given the retrospective analysis, there were no predefined time points for the radiologic assessment of target and nontarget lesions during the treatment, but in most patients computed tomography/ magnetic resonance imaging were repeated every 3 months.

Sample size was calculated a priori. To obtain a $90 \%$ statistical power, with a 2 -sided $\alpha$ error of 0.05 , assuming that $60 \%$ of subjects were diabetic and $40 \%$ were nondiabetic, 267 events (progression or deaths without progression) were needed, and at least 400 patients were to be included to detect a hazard ratio (HR) of progressive disease of 0.67 for diabetic vs nondiabetic patients. With these numbers, assuming that half of the diabetic patients had received metformin and half had not received metformin, $77 \%$ power was anticipated to detect a HR of 0.67 in each subgroup analysis. Data on OS will be available, and the final analysis on survival will be performed when 267 deaths have occurred.

Given the exploratory intent of the analysis, we did not plan hierarchical testing for multiple endpoints or $\alpha$ error splitting. Nevertheless, we applied a correction for multiple testing to the 5 main PFS comparisons (diabetic patients vs nondiabetics, diabetics treated with metformin vs nondiabetics, diabetics not 
treated with metformin vs nondiabetics, diabetics treated with metformin vs. diabetics not treated with metformin, metformin use at multivariable analysis). For these comparisons, $P<.01$ was the threshold for a statistically significant result.

All other sensitivity, exploratory, and subgroup analyses were not corrected for multiplicity. The log-rank test was used to compare the outcomes of different groups. To assess the clinical impact of the parameters under study along with the most relevant known prognostic factors in advanced pNETs (pathologic tumor grading [G1-G2 vs G3]; primary tumor resection; presence of liver, lymph node, and peritoneal metastases), multivariable analysis was performed with the Cox regression model. Multivariable analysis was stratified by the anticancer treatment received, and an additional multivariable analysis was conducted considering only diabetic patients.

To exclude a relevant effect deriving from the time-ontreatment bias (ie, the possibility that early interruption of everolimus or SSA therapy because of disease progression might result in lower patient exposure to these drugs and a consequently lower incidence of diabetes in poorly responding patients), we performed a sensitivity analysis, excluding patients who developed on-treatment diabetes from the diabetic group. We also performed a landmark analysis to exclude a potential immortal time bias related to metformin intake, that is, the possibility that patients taking metformin are those who most benefited from the treatment (everolimus with or without SSAs or SSAs) and consequently were more likely to develop treatment-related diabetes due to longer treatment exposure. In this landmark analysis, we included only patients without disease progression at 3 months after treatment initiation, thus excluding those patients who were less likely to initiate metformin because of early disease progression and treatment interruption. Patients included in the landmark analysis were then divided into 2 groups. Group 1 included patients who were taking metformin at 3 months (both those who were already taking metformin before treatment initiation and those who started metformin within the first 3 months of therapy), and group 2 included patients who were not taking metformin at 3 months (both those who never took metformin and those who started metformin later than 3 months after treatment initiation). In this analysis, patients starting metformin later (ie, those with treatment-potential immortal time bias) were conservatively evaluated as patients who were not exposed to metformin.

Moreover, to evaluate the association between metformin intake and PFS, we considered for each patient the highest metformin dosage reported in medical records during the entire treatment period. We then defined 2 patient categories: (1) low dose: patients receiving metformin up to $1000 \mathrm{mg} /$ day and (2) high dose: patients receiving a dose between 1000 and $3000 \mathrm{mg} /$ day, and we compared PFS in the 2 categories with that of nondiabetic patients.

Finally, given that the high plasma insulin levels could be a major determinant of pNET prognosis and that the potential anticancer effects of metformin may depend on insulinemic status (ie, plasma insulin levels and systemic insulin sensitivity/resistance status ${ }^{20}$ ), in a further analysis we excluded patients who had undergone partial or total pancreatectomy, who were therefore more likely to have different grades of surgery-induced hypoinsulinism. Thereafter, we defined 2 patient populations, the former including patients taking everolimus alone (more likely to be hyperinsulinemic) and the latter including patients treated with SSAs alone (more likely to be hypoinsulinemic).

All statistical tests were 2 -tailed, and $P$ values $<.05$ were considered significant. Statistical analyses were performed using S-Plus (S-PLUS 6.0 Professional, release 1; Insightful Corporation, Seattle, WA).

\section{Results}

\section{Patient Characteristics}

In total, 445 patients were evaluated (Table 1), 16 of whom had multiple endocrine neoplasia type 1 syndrome. Median age was 59 years (interquartile range, 49-69; range, 10-89 years). Overall, 209 (47\%) were nondiabetic, and 236 (53\%) were diabetics, of whom 112 (25\%) received metformin; the remaining 124 patients were treated with insulin $(20 \%)$ or lifestyle recommendations, including diet and physical activity (8\%). Among metformin-treated patients, $69(62 \%)$ received metformin alone, $31(28 \%)$ received metformin plus insulin, and 12 (11\%) received metformin plus incretins. Among diabetic patients, 179 (76\%) had basal T2DM, and 57 (24\%) developed ontreatment diabetes (Supplementary Tables 1 and 2).

Overall, diabetic patients were slightly older (median age, 60 vs 57 years), were more frequently male (59\% vs $47 \%$ ), were less likely to have a G3 tumor (3\% vs 9\%), presented a higher body mass index (24.4 vs $\left.23.0 \mathrm{~kg} / \mathrm{m}^{2}\right)$, more frequently underwent primary tumor resection $(61 \%$ vs $49 \%$ ), and had less frequent liver involvement at initiation of antitumor therapy (87\% vs 95\%) (Table 1). Characteristics of patients with basal or on-treatment diabetes are reported in Supplementary Table 3. Among patients with T2DM, those receiving metformin were less likely to have liver ( $82 \%$ vs $91 \%$ ) and peritoneal (7\% vs $16 \%$ ) metastases and more likely to have lymph node metastases (56\% vs $43 \%$ ) compared with diabetics not treated with metformin (Supplementary Table 4).

\section{Comparison Between Diabetic and Nondiabetic Patients}

In the overall population, median PFS was 23.4 months. Median PFS was 15.1 months in nondiabetic patients and 32.0 months in diabetic subjects, with an absolute difference of 16.9 months in favor of diabetic patients (Figure 1). The HR for progression in diabetic patients vs nondiabetic patients was 0.63 (95\% confidence interval [CI], 0.50-0.80; $P=.0002$ ).

\section{Comparison Between Diabetic Patients Receiving or Not Receiving Metformin}

Median PFS was 44.2 months in metformin-treated patients and 20.8 months in otherwise-treated diabetic patients (Figure 2). There was a 55\% reduction in the risk of progression or death for metformin-treated patients compared with nondiabetic patients (HR, 0.45; 95\% CI, 0.32-0.62; $P<.00001)$. Conversely, we did not find a 
Table 1.Baseline Characteristics of Diabetics and Nondiabetic Patients

\begin{tabular}{|c|c|c|c|}
\hline Baseline characteristic & Nondiabetics $(\mathrm{n}=209)$ & Diabetics $(n=236)$ & $P$ value \\
\hline Median age, $y$ (range) & 57 (10-89) 4 missing & 60 (25-81) 1 missing & .03 \\
\hline \multicolumn{4}{|l|}{ Sex, n (\%) } \\
\hline Male & $99(47)$ & $139(59)$ & .01 \\
\hline Female & $110(53)$ & $97(41)$ & \\
\hline \multicolumn{4}{|l|}{ WHO performance status: $n(\%)$} \\
\hline 0 & $136(65)$ & $161(69)$ & \\
\hline 1 & $57(27)$ & $58(25)$ & \\
\hline 2 & $11(5)$ & $15(6)$ & .27 \\
\hline 3 & $5(2)$ & $1(<1) 1$ missing & \\
\hline \multicolumn{4}{|l|}{ Tumor grade, $\mathrm{n}(\%)$} \\
\hline Grade 1 & $51(25)$ & $66(29)$ & \\
\hline Grade 2 & $137(66)$ & $154(68)$ & .04 \\
\hline Grade 3 & 19 (9) 2 missing & 8 (3) 8 missing & \\
\hline \multicolumn{4}{|l|}{ Functioning tumors, $\mathrm{n}(\%)$} \\
\hline Yes & $12(7)$ & $15(7 \%$ & \\
\hline No & 167 (93) 30 missing & 201 (93) 20 missing & .92 \\
\hline \multicolumn{4}{|l|}{ Treatment } \\
\hline Everolimus \pm SSA & $111(53)$ & $138(58)$ & \\
\hline SSA & $98(47)$ & $98(42)$ & .26 \\
\hline \multicolumn{4}{|l|}{ Previous treatments } \\
\hline Primary tumor resection & $103(49)$ & $143(61)$ & .02 \\
\hline Loco-regional and ablative therapies & 50 (24) 2 missing & $53(22)$ & .67 \\
\hline SSAs & 115 (55) 1 missing & 131 (56) 3 missing & .84 \\
\hline Chemotherapy & 42 (21) 10 missing & 57 (25) 7 missing & .35 \\
\hline PRRT & $52(25)$ & $55(23)$ & .70 \\
\hline \multicolumn{4}{|c|}{ Time from initial diagnosis to everolimus or SSA treatment } \\
\hline$\leq 6 m o$ & $89(43)$ & $83(35)$ & \\
\hline$>6 m o$ to $\leq 2 y$ & $49(24)$ & $57(24)$ & .41 \\
\hline$>2 y$ to $5 y$ & $30(14)$ & $42(18)$ & \\
\hline$>5 y$ & 40 (19) 1 missing & 52 (22) 2 missing & \\
\hline \multicolumn{4}{|l|}{$\mathrm{N}$ of disease sites, $\mathrm{n}(\%)$} \\
\hline 1 & $92(44)$ & $103(44)$ & .78 \\
\hline 2 & $76(36)$ & $92(39)$ & \\
\hline$\geq 3$ & $41(20)$ & $41(17)$ & \\
\hline \multicolumn{4}{|l|}{ Metastasis, n (\%) } \\
\hline Liver & $198(95)$ & $205(87)$ & .004 \\
\hline Nodes & $84(40)$ & $115(49)$ & .06 \\
\hline Lung & $22(11)$ & $21(9)$ & .56 \\
\hline Bone & $36(17)$ & $34(14)$ & .41 \\
\hline Peritoneum & 25 (12) & $28(12)$ & .97 \\
\hline BMI, $\mathrm{kg} / \mathrm{m}^{2}$, median (range) & 23.0 (14.9-34.3) 80 missing & 24.4 (16.6-40.3) 75 missing & .0001 \\
\hline
\end{tabular}

NOTE. Boldface type indicates statistical significance.

BMI, body mass index; PRRT, peptide receptor radionuclide therapy; WHO, World Health Organization.

significant difference in the risk of disease progression between diabetics not treated with metformin and nondiabetics (HR, 0.86; 95\% CI, 0.65-1.13; $P=.26$ ). The hazard ratio for diabetic patients treated with metformin vs diabetic patients not treated with metformin was 0.49 (95\% CI, 0.34-0.69; $P<.0001$ ).

\section{Comparison Between Diabetic Patients Receiving or Not Receiving Metformin According to Everolimus and/or SSA Treatment}

The improved outcome associated with metformin was consistent across different subgroups of patients, stratified according to treatment: everolimus (with or without SSAs) or SSAs alone (Figure 3 and Table 2). Compared with nondiabetic status, diabetes was associated with improved outcome both in patients treated with everolimus with or without SSAs (HR, 0.64; 95\% CI, 0.47-0.87) and in those treated with SSAs alone (HR, 0.57; 95\% CI, 0.38-0.84) ( $P$ for interaction .64). Moreover, compared with nondiabetic patients, the PFS of diabetic patients receiving metformin was longer both in everolimus with or without SSAs and SSAtreated patients: HRs were 0.45 (95\% CI, 0.30-0.68) and 0.38 (95\% CI, 0.21-0.67), respectively ( $P$ for interaction $=$ .67). Conversely, we did not find any significant PFS difference between nondiabetic patients and diabetic patients not treated with metformin, both in everolimus with or without SSAs and SSA-treated patients: HRs were 0.89 (95\% CI, $0.62-1.26)$ and 0.77 (95\% CI, 0.49-1.20), respectively ( $P$ for interaction $=.56$ ). 


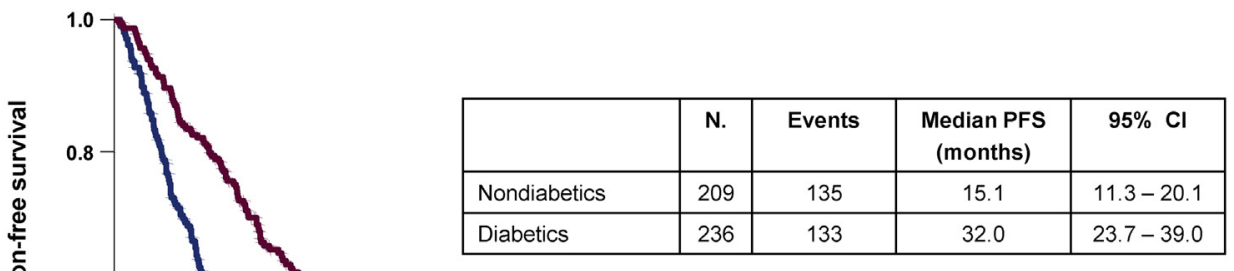

$0.63(95 \% \mathrm{Cl} 0.50-0.80), P=.0002$

\section{Multivariable Analysis}

At multivariable analysis stratified by treatment, several known prognostic factors in advanced pNETs, such as tumor grading (G1 or G2 vs. G3) and liver metastases, were confirmed to be prognostic (Table 3). Glycemic status was not associated with prognosis. Conversely, metformin use was associated with improved prognosis after adjustment for other prognostic factors, with an HR for PFS of 0.53 (95\% CI, 0.34-0.82; $P=.004$ ) in the overall population. The same finding was reported in a multivariable analysis of the subgroup of diabetic patients (HR, 0.46; 95\% CI, 0.29-0.72; $P=.001$ ) (Supplementary Table 5).

\section{Sensitivity and Landmark Analysis}

After excluding patients with on-treatment diabetes, metformin use in diabetics remained associated with improved PFS compared with the cohort of nondiabetic
Figure 2. Kaplan-Meier plot of PFS among nondiabetic patients, diabetics treated with metformin (MET), and diabetics not receiving metformin but treated with insulin or diet.

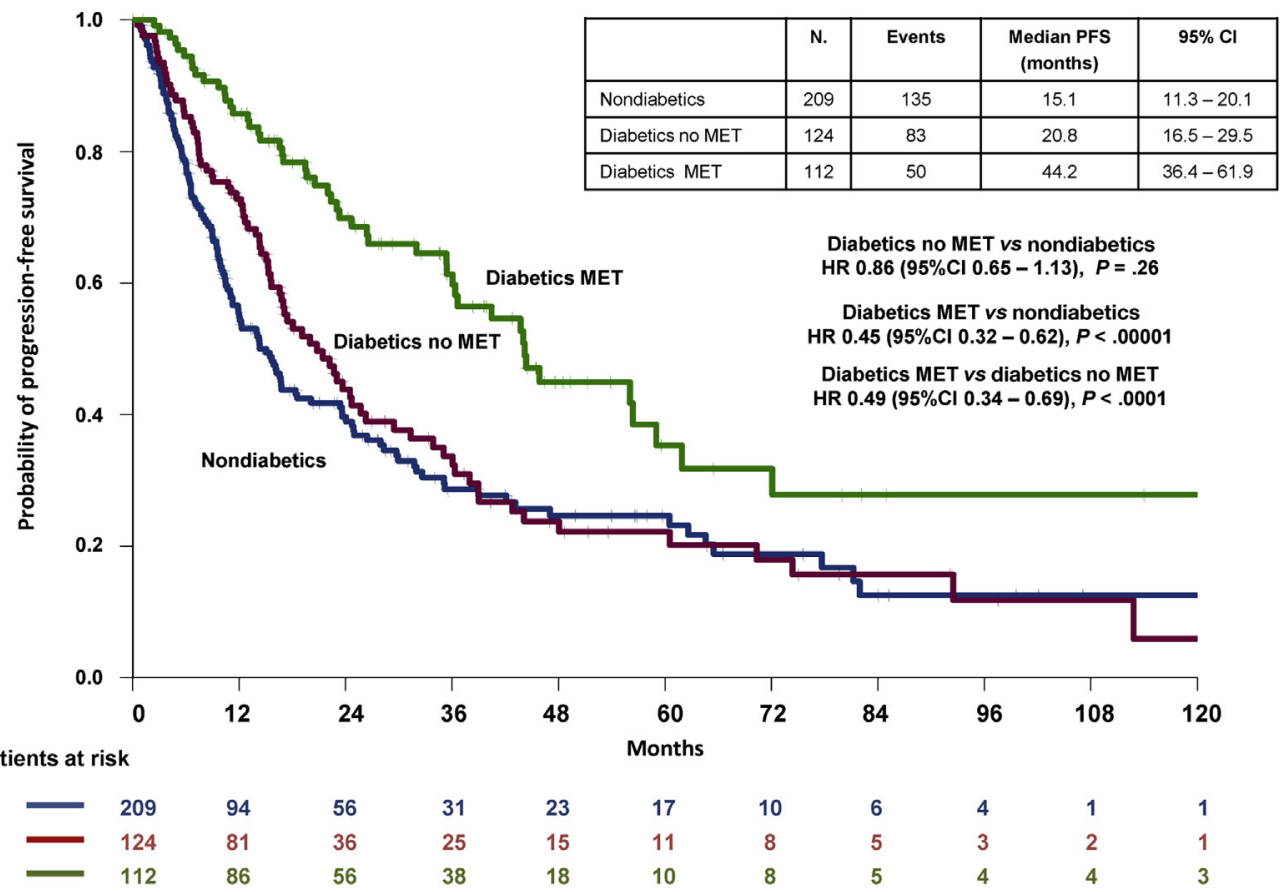


Figure 3. Forest plot showing the effect of glycemia on PFS in patient subgroups according to the oncological treatment administered. EVE, everolimus; pts, patients.

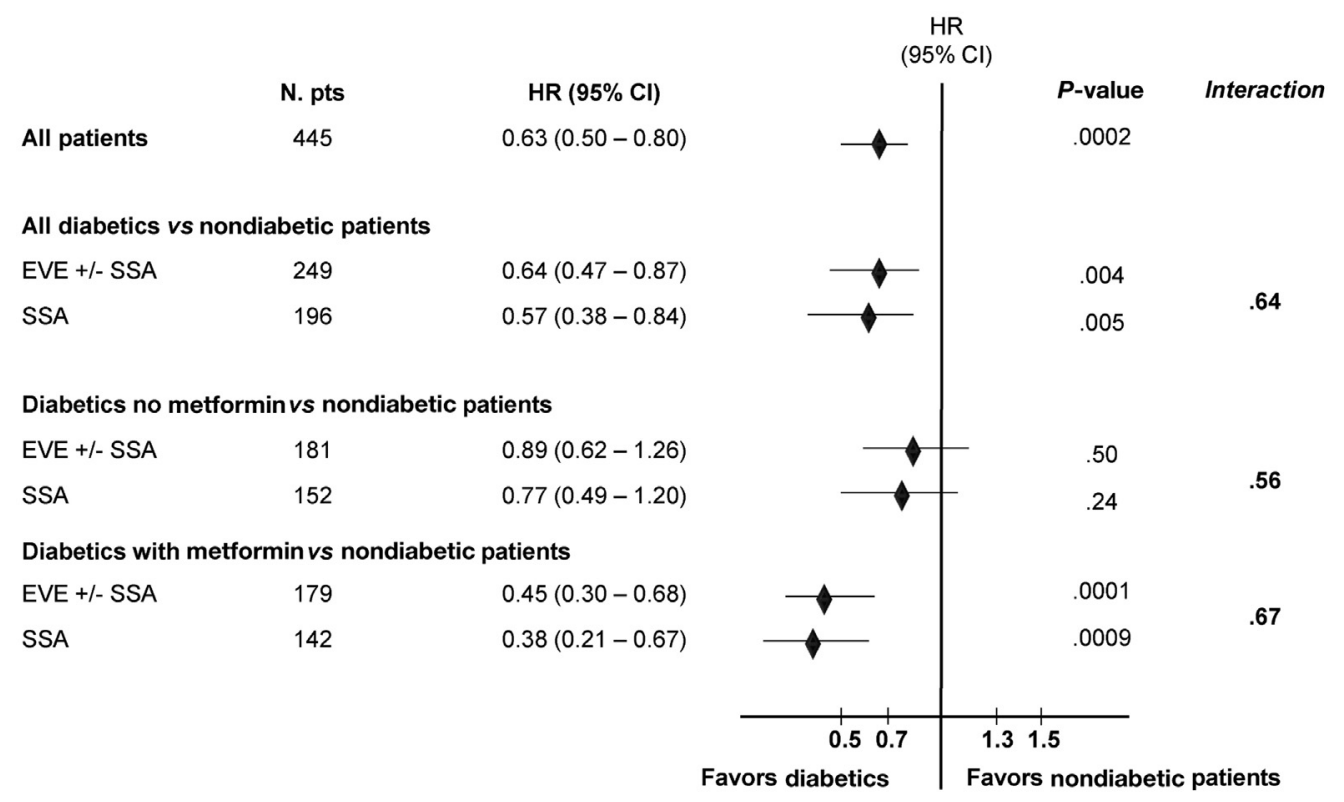

patients (Supplementary Figure 2 and Supplementary Table 6). Moreover, the landmark analysis performed at 3 months showed longer survival in patients who started metformin before or within 3 months from treatment initiation compared with patients who never took metformin or who started taking it later, with PFSs of 43.7 and 23.3 months, respectively (HR, 0.64; 95\% CI, 0.43-0.93; $P=.02$ ) (Supplementary Figure 3 and Supplementary Table 7).

\section{Influence of Metformin Dosage}

According to available data, 45 patients received lowdose metformin (median, $1000 \mathrm{mg}$; interquartile range, 850-1000), and 60 patients received high-dose metformin (median, $2000 \mathrm{mg}$; interquartile range, 1500-2000). At survival analysis, we found no evidence of a trend in PFS differences according to metformin dosage; indeed, median PFS was 45.9 months for patients receiving low metformin

Table 2.PFS in Subgroups of Patients Receiving Everolimus With or Without SSA or SSA Alone

\begin{tabular}{|c|c|c|c|c|c|}
\hline Variable & $\begin{array}{l}\text { Nondiabetics, median } \\
\text { PFS, mo }(95 \% \mathrm{Cl})\end{array}$ & $\begin{array}{l}\text { Diabetics, median } \\
\text { PFS, mo }(95 \% \mathrm{Cl})\end{array}$ & Delta & HR & $P$ value \\
\hline $\begin{array}{c}\text { Everolimus } \pm \text { SSA }(\mathrm{n}=111 \mathrm{ND} \\
\text { patients vs } 138 \mathrm{D} \text { patients })\end{array}$ & $12.1(9.6-16.7)$ & $22.7(17.4-36.3)$ & 10.6 & $0.64(0.47-0.87)$ & .004 \\
\hline \multirow[t]{2}{*}{ SSA ( $\mathrm{n}=98 \mathrm{ND}$ patients vs $98 \mathrm{D}$ pts) } & $24.0(12.3-35.1)$ & $36.6(33.9-92.5)$ & 12.6 & $0.57(0.38-0.84)$ & $\begin{array}{c}.005 \text { Interaction } \\
P=.64\end{array}$ \\
\hline & & $\begin{array}{l}\text { Metformin, median } \\
\text { PFS, mo }(95 \% \mathrm{Cl})\end{array}$ & & & \\
\hline $\begin{array}{c}\text { Everolimus } \pm \text { SSA ( } n=111 \mathrm{ND} \\
\text { patients vs } 68 \mathrm{M} \text { patients) }\end{array}$ & $12.1(9.6-16.7)$ & $43.7(26.4-61.9)$ & 31.6 & $0.45(0.30-0.68)$ & .0001 \\
\hline \multirow[t]{2}{*}{ SSA ( $n=98$ ND patients vs $44 M$ patients) } & $24.0(12.3-35.1)$ & $45.9(36.4-N A)$ & 21.9 & $0.38(0.21-0.67)$ & $\begin{array}{c}.0009 \text { Interaction } \\
P=.67\end{array}$ \\
\hline & & $\begin{array}{l}\text { Insulin, median } \\
\text { PFS, mo }(95 \% \mathrm{Cl})\end{array}$ & & & \\
\hline $\begin{array}{l}\text { Everolimus } \pm \text { SSA ( } n=111 \text { ND } \\
\text { patients vs } 53 \text { I patients) }\end{array}$ & $12.1(9.6-16.7)$ & $17.4(12.7-35.1)$ & 5.3 & $0.79(0.54-1.17)$ & .24 \\
\hline \multirow[t]{2}{*}{ SSA ( $n=98$ ND patients vs 38 I patients) } & $24.0(12.3-35.1)$ & $33.9(19.1-\mathrm{NA})$ & 9.9 & $0.78(0.47-1.27)$ & $\begin{array}{c}.31 \text { Interaction } \\
P=.87\end{array}$ \\
\hline & & $\begin{array}{l}\text { Not metformin, median } \\
\quad \text { PFS, } m o(95 \% \mathrm{Cl})\end{array}$ & & & \\
\hline $\begin{array}{c}\text { Everolimus } \pm \text { SSA ( } n=111 \mathrm{ND} \\
\text { patients vs } 70 \text { NM patients) }\end{array}$ & $12.1(9.6-16.7)$ & $15.6(13.0-22.7)$ & 3.5 & $0.89(0.62-1.26)$ & .50 \\
\hline SSA ( $n=98 \mathrm{~N}$ patients vs 54 NM patients) & $24.0(12.3-35.1)$ & $31.3(22.2-70.3)$ & 7.3 & $0.77(0.49-1.20)$ & $\begin{array}{c}.24 \text { Interaction } \\
P=.56\end{array}$ \\
\hline
\end{tabular}

D, diabetic; I, insulin; M, metformin; NA, not applicable; ND, nondiabetic; NM, not metformin. 
Table 3. Results of the Multivariable Analysis Stratifying the Model by Treatment (Everolimus/Everolimus + SSA/SSA)

\begin{tabular}{llcr}
\hline \multicolumn{1}{c}{ Covariate } & \multicolumn{1}{c}{ Subgroups } & Hazard ratio $(95 \% \mathrm{Cl})$ & $P$ value \\
\hline Age & $>70$ y vs $<70$ y & $1.33(0.98-1.79)$ & .06 \\
Sex & Female vs male & $1.15(0.89-1.49)$ & .29 \\
Glycemia & Diabetics vs nondiabetics & $0.98(0.63-1.51)$ & .91 \\
Metformin & Metformin vs no & $0.53(0.34-0.82)$ & .004 \\
Insulin & Insulin vs no & $0.88(0.58-1.33)$ & .55 \\
Grading & G3 vs G1 or G2 & $2.98(1.87-4.75)$ & $<.0001$ \\
Primary tumor resection & Yes vs no & $0.77(0.60-0.99)$ & .04 \\
Liver metastases & Yes vs no & $1.88(1.06-3.36)$ & .03 \\
Node metastases & Yes vs no & $0.82(0.63-1.06)$ & .13 \\
Peritoneal metastases & Yes vs no & $1.12(0.74-1.69)$ &
\end{tabular}

dosages and 36.1 months for patients receiving high dosages, which were both significantly longer than the median PFS of 15.7 months observed in nondiabetic patients (HR for low metformin group vs nondiabetic group, $0.44 ; 95 \% \mathrm{CI}$, $0.28-0.71 ; P<.001 ;$ HR for high metformin group vs nondiabetic group, $0.70 ; 95 \% \mathrm{CI}, 0.56-0.86 ; P=.001$ ).

\section{Effect of T2DM and Metformin Use in Patients Treated With Everolimus Alone}

Because everolimus and SSAs cause hyperglycemia through different mechanisms, we performed a separate analysis to investigate the potential impact of T2DM diagnosis and metformin use on the PFS of patients treated with everolimus alone (Supplementary Table 8). Only 37 patients received everolimus alone, which limited the statistical power of this analysis. We found no significant differences between the PFS of nondiabetic and diabetic patients $(P=.45)$ or between diabetics receiving or not receiving metformin and nondiabetic patients ( $P=.1$ and $P=.28$, respectively).

\section{Effect of Metformin in Patient Subgroups With Potentially Different Plasma Insulinemic Status}

Overall, 16 patients treated with everolimus alone did not receive any pancreatic surgery; 12 of these did not receive metformin, and 4 were treated with metformin. Median PFS was 18.4 months in patients who did not receive metformin, and it was not reached in patients who received metformin (HR, 0.26; 95\% CI, 0.03-2.47).

Among patients treated with SSA alone, 61 did not receive any pancreatic surgery; of these, 46 did not receive metformin, and 15 received it. Median PFS was 11.9 and 44.2 months in these subgroups, respectively (HR, 0.46; 95\% CI, 0.20-1.08).

\section{Discussion}

In this multicenter, retrospective study of 445 patients with advanced pNETs, we found that type 2 diabetes mellitus, either diagnosed before treatment initiation or emerging during everolimus therapy with or without SSA, was associated with longer PFS regardless of the specific anticancer treatment received. Moreover, when stratifying diabetic patients according to antidiabetic treatment, those receiving metformin had longer PFSs than nondiabetic ones, whereas no differences were observed between nondiabetic patients and those with T2DM treated only with insulin or diet modifications. The benefit associated with metformin was independent of the antitumor treatment. In our opinion, the results of the multivariable analysis represent the most relevant finding of the study, because they suggest that it is metformin use-rather than glycemic status-that is associated with an improved prognosis in advanced pNET patients.

Given that everolimus, SSAs, or both can induce diabetes, the observed improved prognosis in the group of diabetic patients could simply reflect longer exposure to an effective anticancer treatment (immortal time bias). However, the sensitivity analysis that we performed by eliminating patients who developed on-treatment diabetes seems to exclude this possibility and reinforces the conclusion that metformin use correlates with improved patient prognosis. These findings are further strengthened by the landmark analysis, which showed longer survival in patients who started metformin before or within 3 months from treatment initiation than patients who never took metformin or who started it later.

Our findings are consistent with recent retrospective evidence, including a meta-analysis of 20 retrospective studies that showed a $38 \%$ reduced risk of death in metformin-receiving cancer patients with T2DM. ${ }^{29}$ Several prospective studies are testing the efficacy of metformin in combination with standard treatments in many solid cancers. These studies are investigating metformin also in nondiabetic patients, who represent the majority of cancer patients.

To date, only 3 prospective randomized studies of patients with unresectable pancreatic exocrine tumors have been published. ${ }^{30-32}$ However, these studies failed to show any advantage from combining metformin with standard chemotherapy treatments.

This discrepancy may stem from the following factors. (1) In retrospective studies, metformin is taken only by those patients diagnosed with diabetes. For various reasons, including specific metabolic or tumor biology profiles, these patients could benefit from metformin, although nondiabetic 
ones could not. Because in prospective studies metformin is given to both diabetic and nondiabetic patients, it could prove ineffective at improving prognosis in the overall population. (2) Many patients included in retrospective studies started taking metformin several months, or even years, before tumor diagnosis and treatment. Because metformin could affect the tumorigenesis process by altering systemic metabolism or proliferation of tumor precursor cells, malignancies evolving under chronic metformin exposure may display less aggressive behavior. This could result in a clinical advantage for patients under metformin treatment in retrospective studies, whereas this compound could be ineffective when given to patients at the initiation of oncological treatment. (3) Retrospective studies are subject to poor reporting bias, which can affect the assessment of diabetes duration, the use and dosage of antidiabetic drugs, or both.

In this study, we did not disclose any significant association between metformin dose and PFS. However, this analysis presents major limitations. First, patients taking metformin had received this drug at any time during their clinical history; therefore, there was no predefined time point for the assessment of metformin dose during the course of diabetes. Second, given that treatment for hyperglycemia can change over time, we cannot rule out that metformin dosage has been frequently changed in the evaluated patients on the basis of diabetes control, emerging comorbidities, or need for the association of other antidiabetic drugs during the course of disease. Therefore, we believe that, because of the prolonged PFS reported in many patients, there could have been considerable variation in metformin dosage, and the highest dosage may not well reflect global exposure to metformin during the treatment period. Moreover, the reported metformin dosage for individual patients may not necessarily mirror the average exposure dosage over months or years of diabetes management. Therefore, we believe that the absence of a doseeffect relationship regarding metformin use cannot be considered definitive. Prospective trials with detailed information about metformin dosage and its changes during the treatment are, however, required to investigate this major issue.

It is still unclear whether potential metformin anticancer effects are mediated by changes in systemic metabolism

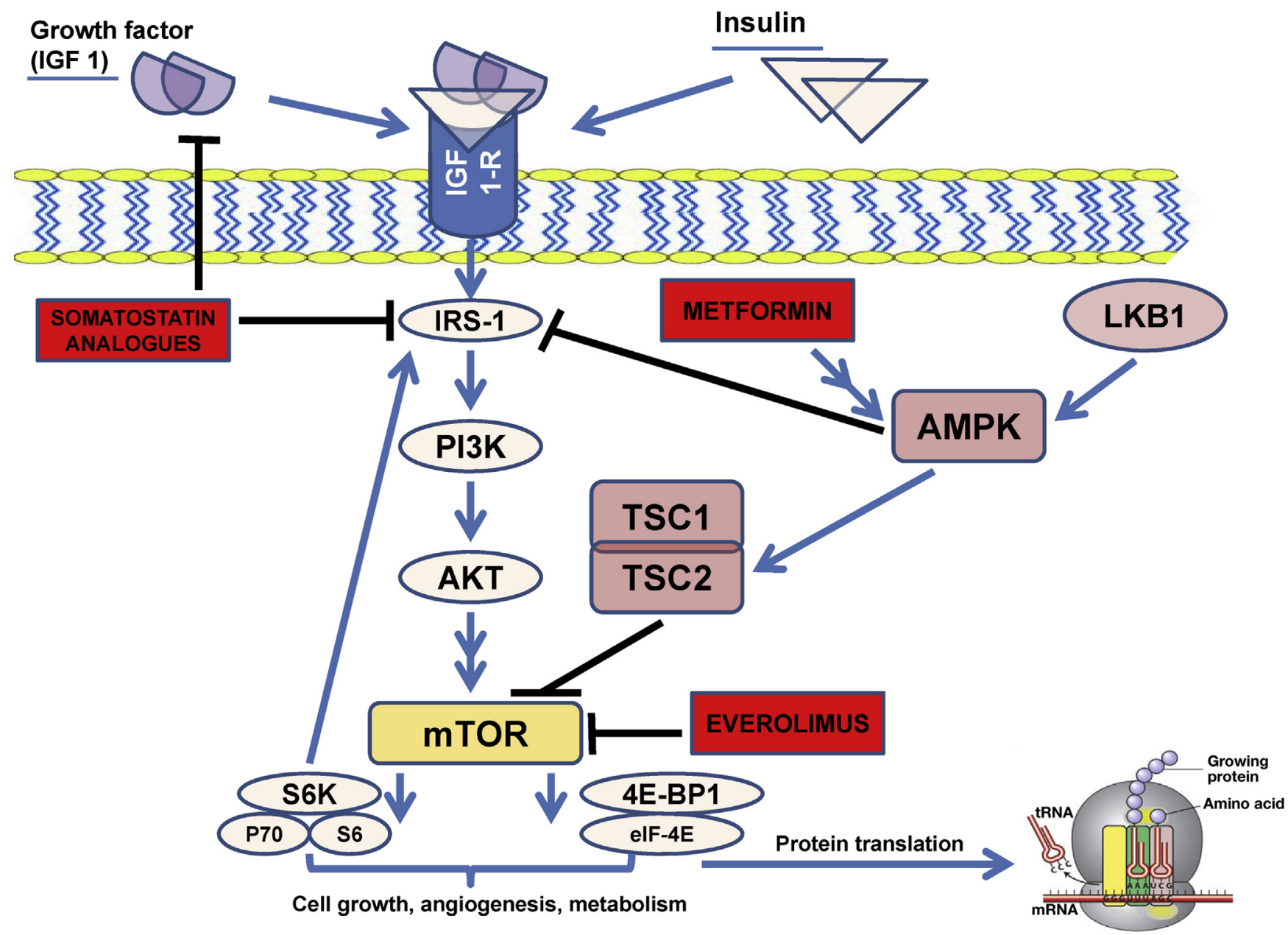

Figure 4. Interplay between IGF-1/IGF1R/PI3K/Akt/mTOR and AMPK pathways. Potential synergistic activity among somatostatin analogues, everolimus, and metformin may derive from inhibition of the IGF-1/IGF1R/PI3K/Akt/mTOR axis at different levels of the cascade. Akt, protein kinase B; IGF-I, insulin-like growth factor I; IGFIR, insulin-like growth factor I receptor; PI3K, phosphatidylinositol 3-kinase; tRNA, transfer RNA. Modified from Pusceddu et al. ${ }^{25}$ 
(blood glycemia and insulinemia), through cell-autonomous anticancer effects, or through a combination of both. ${ }^{17,18}$ Our finding that the glycemic status was not associated with patient outcome regardless of metformin use suggests that the role of metformin in reducing glycemia is likely poorly relevant in patients with advanced pNETs.

With respect to insulinemia, existing evidence on the potential oncogenic role of insulin suggests that even physiological concentrations of insulin could stimulate cancer growth. ${ }^{33}$ In our study, measurements of blood insulin concentration were not available; therefore, we could not conclude that patients receiving insulin therapy actually had higher blood insulin concentrations than nondiabetic patients. Nevertheless, the fact that diabetic patients receiving insulin did not have reduced PFS suggests that insulin therapy is not associated with a worse clinical outcome, as confirmed by the multivariable analysis.

Based on the lack of an association between blood glucose levels and insulin intake with patient prognosis, we believe that metformin might be associated with an improved prognosis in patients with pNET by displaying direct, cell-autonomous anticancer effects. Furthermore, metformin was associated with longer PFS in both patients treated with everolimus, which is known to reduce peripheral tissue sensitivity to insulin and to cause hyperinsulinemia, and in those receiving SSAs, which can reduce blood insulin levels. ${ }^{17,18}$ This finding may further support the notion that mechanisms other than the reduction of circulating insulin levels might contribute to the prolonged PFS in patients taking metformin. Another argument in favor of this hypothesis can be found in the results of our subgroup analysis, which, although performed in a small number of patients, suggests that metformin-associated effects do not seem mediated by the reduction of blood glucose concentrations, whereas cell-autonomous, antitumor effects could be more prominent.

Given pNET dependence on the insulin-like growth factor I receptor/phosphatidylinositol 3-kinase/protein kinase $\mathrm{B} / \mathrm{mTOR}$ axis, the biological rationale for combining metformin with everolimus (ie, strengthening of mTOR pathway inhibition through the AMPK-TSC1/2-mTOR axis) or SSAs (through synergistic inhibition of the insulin-like growth factor-I receptor/phosphatidylinositol 3-kinase/protein kinase B/mTOR pathways) may exist (Figure 4). ${ }^{25}$

\section{Conclusions}

With all the limitations of retrospective studies, our results showed, for the first time, that in a population of patients with advanced pNETs treated with everolimus, SSAs, or both, diabetic subjects receiving metformin had statistically and clinically meaningful prolonged PFS compared with both nondiabetic patients and diabetics treated with insulin or diet.

Although causal relationships cannot be established, these findings suggest that metformin could have some antitumor effects in the treatment of patients with advanced pNETs. Based on our results, 2 prospective, pilot, phase II studies are currently ongoing at the Istituto Nazionale
Tumori (Milan, Italy) to assess metformin in combination with both SSAs and everolimus in the treatment of advanced pNETs (MetNET-1 trial, NCT02294006) and in combination with SSAs in lung and small bowel neuroendocrine tumors (MetNET-2 trial, NCT02823691).

Author contributions: Study concept and design: Sara Pusceddu, Massimo Di Maio, Vincenzo Mazzaferro, and Filippo de Braud. Acquisition of data: all authors. Analysis and interpretation of data: all authors. Drafting of the manuscript and critical revision of the manuscript for important intellectual content: all authors. Statistical analysis: Sara Pusceddu, Massimo Di Maio, Vincenzo Mazzaferro, and Filippo de Braud. Study supervision: all authors.

\section{Supplementary Material}

Note: To access the supplementary material accompanying this article, visit the online version of Gastroenterology at www.gastrojournal.org, and at https://doi.org/10.1053/ j.gastro.2018.04.010.

\section{References}

1. Hallet J, Law $\mathrm{CH}$, Cukier M, et al. Exploring the rising incidence of neuroendocrine tumors: a population-based analysis of epidemiology, metastatic presentation, and outcomes. Cancer 2015;121:589-597.

2. Yao JC, Lagunes DR, Kulke MH, et al. Targeted therapies in neuroendocrine tumors (NET): clinical trial challenges and lessons learned. Oncologist 2013;18:525-532.

3. Fendrich V, Waldmann J, Bartsch DK, et al. Surgical management of pancreatic endocrine tumors. Nat Rev Clin Oncol 2009;6:419-428.

4. Halfdanarson TR, Rabe KG, Rubin J, et al. Pancreatic neuroendocrine tumors (PNETs): incidence, prognosis and recent trend toward improved survival. Ann Oncol 2008;19:1727-1733.

5. Yao JC, Shah MH, Ito T, et al. Everolimus for advanced pancreatic neuroendocrine tumors. New Engl J Med 2011;364:514-523.

6. Raymond E, Dahan L, Raoul JL, et al. Sunitinib malate for the treatment of pancreatic neuroendocrine tumors. New Engl J Med 2011;364:501-513.

7. Strosberg J, El-Haddad G, Wolin E, et al. Phase 3 trial of 177Lu-dotatate for midgut neuroendocrine tumors. N Engl J Med 2017;376:125-135.

8. Caplin ME, Pavel M, Cwikla JB, et al. Lanreotide in metastatic enteropancreatic neuroendocrine tumors. New Engl J Med 2014;371:224-233.

9. Leoncini E, Carioli G, La Vecchia C, et al. Risk factors for neuroendocrine neoplasms: a systematic review and meta-analysis. Ann Oncol 2016;27:68-81.

10. Haugvik SP, Hedenstrom P, Korsaeth E, et al. Diabetes, smoking, alcohol use, and family history of cancer as risk factors for pancreatic neuroendocrine tumors: a systematic review and meta-analysis. Neuroendocrinology 2015;101:133-142.

11. Vander Heiden MG, Cantley LC, Thompson CB. Understanding the Warburg effect: the metabolic requirements of cell proliferation. Science 2009;324:1029-1033. 
12. Godsland IF. Insulin resistance and hyperinsulinaemia in the development and progression of cancer. Clin Science 2009;118:315-329.

13. Vernieri C, Casola S, Foiani M, et al. Targeting cancer metabolism: dietary and pharmacologic interventions. Cancer Discover 2016;6:1315-1333.

14. Han X, Wang D, Kuang T, et al. Glucagonoma syndrome: report of one case. Transl Gastroenterol Hepatol 2016; 1:70.

15. Struyvenberg MR, Fong ZV, Martin CR, et al. Impact of treatments on diabetic control and gastrointestinal symptoms after total pancreatectomy. Pancreas 2017; 46:1188-1195.

16. Beger HG, Poch B, Mayer B, Siech M. New onset of diabetes and pancreatic exocrine insufficiency after pancreaticoduodenectomy for benign and malignant tumors: a systematic review and meta-analysis of longterm results. Ann Surg 2018;267:259-270.

17. Vergès $B$, Cariou B. mTOR inhibitors and diabetes. Diabetes Res Clin Pract 2015;110:101-108.

18. Steffin B, Gutt B, Bidlingmaier M, et al. Effects of the long-acting somatostatin analogue Lanreotide Autogel on glucose tolerance and insulin resistance in acromegaly. Eur J Endocrinol 2006;155:73-78.

19. Libby G, Donnelly LA, Donnan PT, et al. New users of metformin are at low risk of incident cancer: a cohort study among people with type 2 diabetes. Diabetes Care 2009;32:1620-1625.

20. Pierotti MA, Berrino F, Gariboldi M, et al. Targeting metabolism for cancer treatment and prevention: metformin, an old drug with multi-faceted effects. Oncogene 2013;32:1475-1487.

21. Sonnenblick A, Agbor-Tarh D, Bradbury I, et al. Impact of diabetes, insulin, and metformin use on the outcome of patients with human epidermal growth factor receptor 2positive primary breast cancer: analysis from the ALTTO phase III randomized trial. J Clin Oncol 2017;35: 1421-1429.

22. Klubo-Gwiezdzinska J, Costello J Jr, Patel A, et al. Treatment with metformin is associated with higher remission rate in diabetic patients with thyroid cancer. J Clin Endocrinol Metab 2013;98:3269-3279.

23. Meng F, Song L, Wang W. Metformin improves overall survival of colorectal cancer patients with diabetes: a meta-analysis. J Diabetes Res 2017;2017:5063239.

24. Shackelford DB, Shaw RJ. The LKB1-AMPK pathway: metabolism and growth control in tumour suppression. Nat Rev Cancer 2009;9:563-575.

25. Pusceddu S, Buzzoni R, Vernieri C, et al. Metformin with everolimus and octreotide in pancreatic neuroendocrine tumor patients with diabetes. Future Oncol 2016; 12:1251-1260.
26. Lloyd RV, Osamura RY, Klöppel G, Rosai J. Neoplasms of the neuroendocrine pancreas. In: Lloyd RV, Osamura RY, Klöppel G, Rosai J, eds. WHO classification of tumours of endocrine organs. WHO/IARC classification of tumours. Volume 10. 4th ed. Geneva: World Health Organization, 2017:209-239.

27. American Diabetes Association. Diagnosis and classification of diabetes mellitus. Diabetes Care 2017;40 (Suppl 1):S12-S13.

28. Eisenhauer EA, Therasse P, Bogaerts J, et al. New response evaluation criteria in solid tumours: revised RECIST guideline (version 1.1). Eur J Cancer 2009; 45:228-247.

29. Yin M, Zhou J, Gorak EJ, et al. Metformin is associated with survival benefit in cancer patients with concurrent type 2 diabetes: a systematic review and meta-analysis. Oncologist 2013;18:1248-1255.

30. Kordes S, Pollak MN, Zwinderman AH, et al. Metformin in patients with advanced pancreatic cancer: a doubleblind, randomised, placebo-controlled phase 2 trial. Lancet Oncol 2015;16:839-847.

31. Braghiroli MI, de Celis Ferrari AC, Pfiffer TE, et al. Phase II trial of metformin and paclitaxel for patients with gemcitabine-refractory advanced adenocarcinoma of the pancreas. Ecancermedicalscience 2015;9:563.

32. Reni M, Dugnani E, Cereda S, et al. (Ir)relevance of metformin treatment in patients with metastatic pancreatic cancer: an open-label, randomized phase II trial. Clin Cancer Res 2016;22:1076-1085.

33. Ding XZ, Fehsenfeld DM, Murphy LO, et al. Physiological concentrations of insulin augment pancreatic cancer cell proliferation and glucose utilization by activating MAP kinase, PI3 kinase and enhancing GLUT-1 expression. Pancreas 2000;21:310-320.

Received March 6, 2017. Accepted April 6, 2018.

Reprint requests

Address requests for reprints to: Sara Pusceddu, MD, Department of Medical Oncology Unit-1, Fondazione IRCCS Istituto Nazionale dei Tumori and ENETS Center of Excellence, Via Venezian 1, 20133 Milano, Italy. e-mail: sara.pusceddu@istitutotumori.mi.it; fax: +(0039) 0223902149.

\section{Conflict of interests}

Sara Pusceddu received honoraria from Novartis, Ipsen, Italfarmaco, Pfizer, and Advanced Accelerator Applications. Massimo Di Maio received honoraria from AstraZeneca, Bayer, Boehringer-Ingelheim, Eli Lilly, Merck Sharp \& Dohme, and Novartis. Toni Ibrahim received honoraria from Pfizer, Eisai, and Pharmamar. Luca Giacomelli received honoraria from Bayer, Eisai, Otsuka, Helssinn, LeoPharma, Grunenthal, Pierre-Fabre, Indena, Abbvie, CSL Behring, Santhera, Recordati. The remaining authors disclose no conflicts.

\section{Funding}

This work was supported by the Italian Association for Neuroendocrine Tumors (It.A.Net) and the NEXT TIME NET group. Editorial assistance for the preparation of this manuscript was provided by Sara Parodi, PhD, on behalf of Content Ed Net; this assistance was funded by an unrestricted grant from Novartis. 
Inclusion Criteria

Well-differentiated pNETs*

Advanced/recurrent

EVE and/or SSA therapy

PS (ECOG) 0-3
Exclusion Criteria

Poorly differentiated

Well-differentiated GEP-NETs

except for pancreatic ones

Primary objective

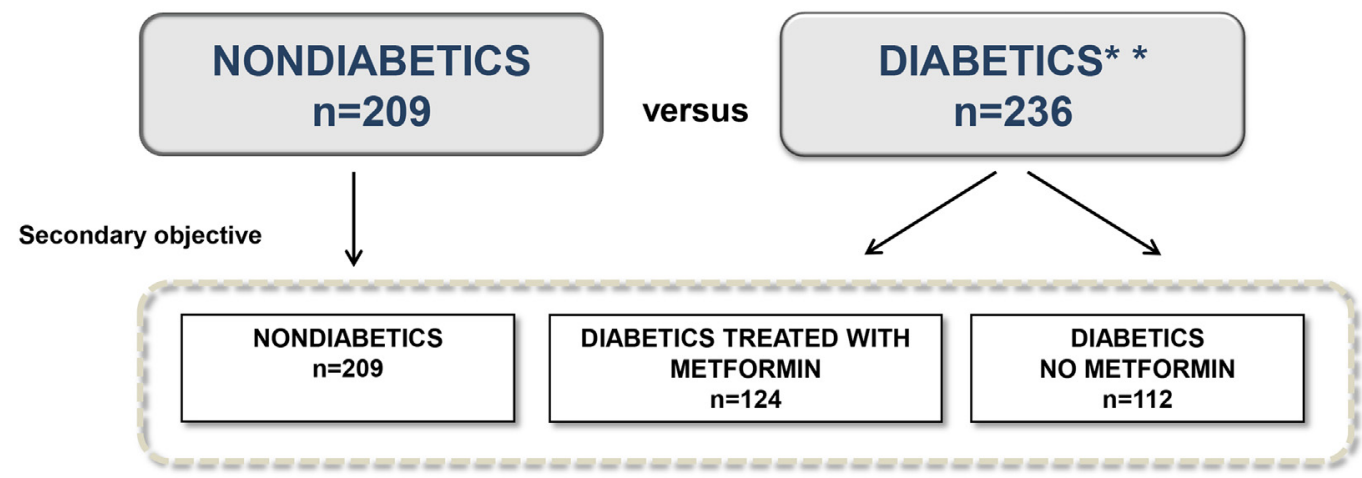

Supplementary Figure 1. PRIME-NET study design. *Well-differentiated pNETs are well-differentiated pancreatic neuroendocrine tumors with Ki-67 score < 50\% according to 2017 pNET World Health Organization classification. ${ }^{* *}$ Type 2 diabetes: patients with fasting plasma glucose level $\geq 126 \mathrm{mg} / \mathrm{dL}(7.0 \mathrm{mmol} / \mathrm{L})$, hemoglobin $\mathrm{A} 1 \mathrm{c} \geq 6.5 \%$ (48 mmol/L), or random plasma glucose level $\geq 200 \mathrm{mg} / \mathrm{dL}$ (11.1 mmol/L) with reported classic symptoms of hyperglycemia or hyperglycemic crisis; ECOG, Eastern Cooperative Oncology Group; EVE, everolimus; GEP-NET, gastroentero-pancreatic neuroendocrine tumor; PS, performance status.

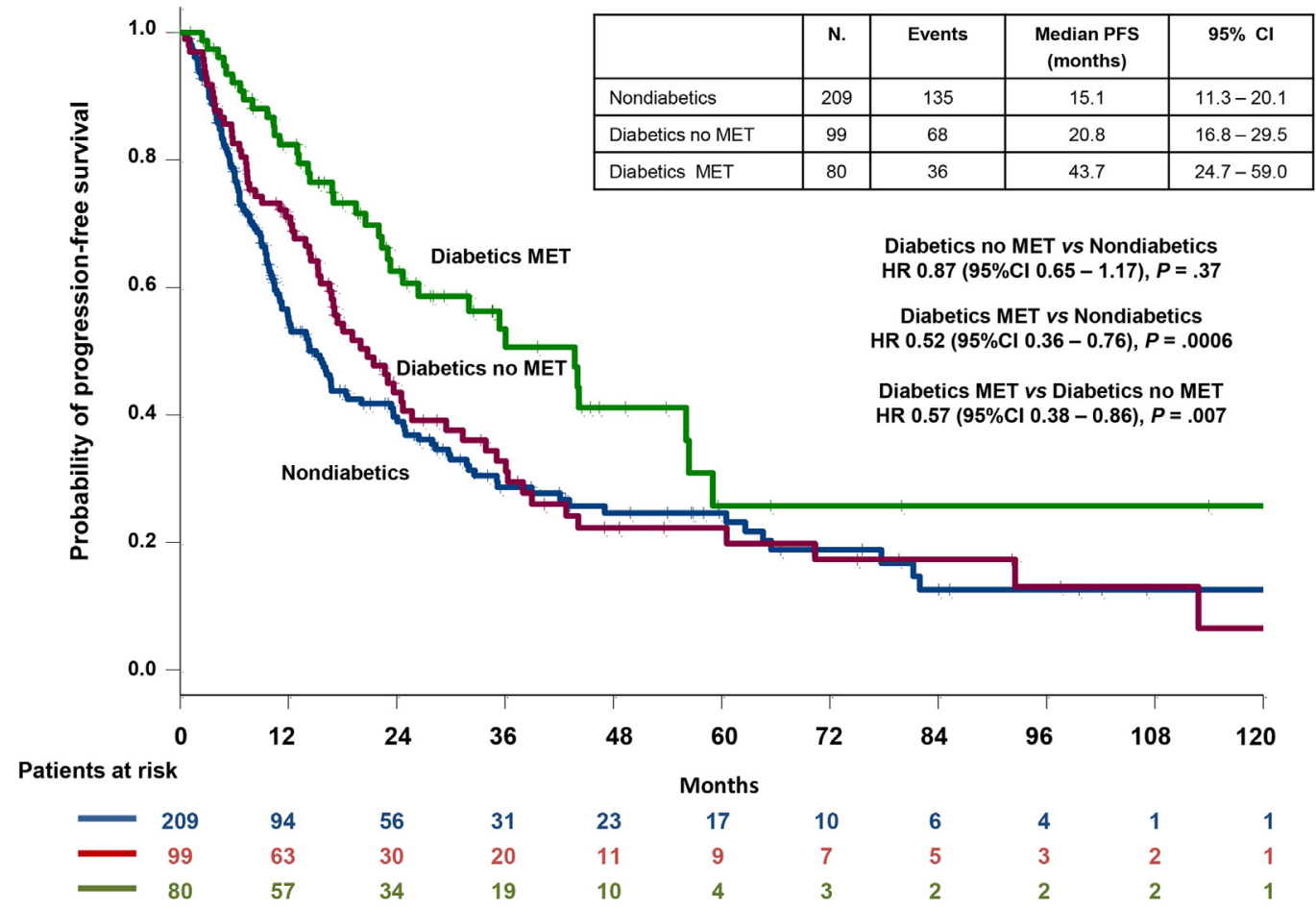

Supplementary Figure 2. Kaplan-Meier plot of PFS among metformin (MET) recipients, patients taking insulin or following a modified diet, and nondiabetic subjects, with the exclusion of patients developing on-treatment diabetes (sensitivity analysis). 


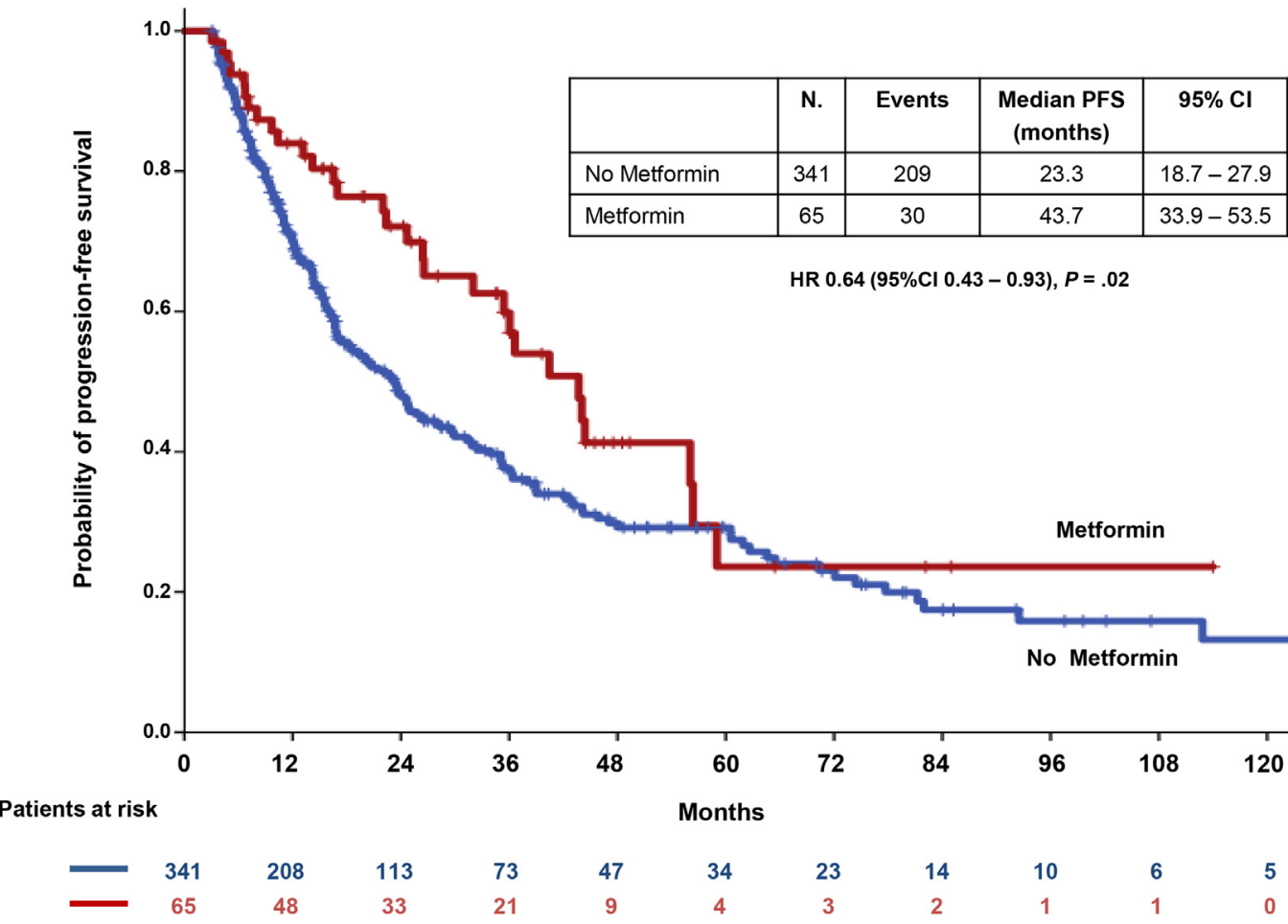

Supplementary Figure 3. Kaplan-Meier plot of PFS among patients receiving metformin vs patients not receiving metformin 3 months after treatment initiation (landmark analysis). 
Supplementary Table 1.Distribution of Patients According to Oncological Treatment Received

\begin{tabular}{lcccc}
\hline Treatment & $\begin{array}{c}\text { Nondiabetic patients } \\
(\mathrm{n}=209)\end{array}$ & $\begin{array}{c}\text { Diabetics } \\
(\mathrm{n}=236)\end{array}$ & $\begin{array}{c}\text { Diabetics treated with } \\
\text { metformin }(\mathrm{n}=112)\end{array}$ & $\begin{array}{c}\text { Diabetics not treated with } \\
\text { metformin }(\mathrm{n}=124)\end{array}$ \\
\hline Everolimus & $111(53)$ & $138(58)$ & $68(61)$ & $70(56)$ \\
EVE alone & $20(8)$ & $17(7)$ & $9(8)$ & $8(6)$ \\
EVE + SSA & $91(43)$ & $121(51)$ & $59(53)$ & $62(50)$ \\
SSA & $98(47)$ & $98(42)$ & $44(39)$ & $54(44)$ \\
\end{tabular}

NOTE. All values are expressed as $\mathrm{n}(\%)$.

EVE, everolimus.

Supplementary Table 2. Distribution of patients treated with everolimus with or without SSA

\begin{tabular}{|c|c|c|c|c|}
\hline Characteristics of patients & $\mathrm{n}$ & $\%$ & $\mathrm{n}$ & $\%$ \\
\hline Everolimus + SSA & 212 & $(85)$ & - & - \\
\hline Nondiabetic patients & 111 & $(45)$ & 98 & $(50)$ \\
\hline Diabetic patients & 138 & (55) & 98 & (50) \\
\hline Metformin & 68 & $(27 \%)$ & 44 & (22) \\
\hline
\end{tabular}


Supplementary Table 3. Baseline Characteristics of Patients With Diabetes at Diagnosis and Those Who Developed Diabetes On-Treatment

\begin{tabular}{|c|c|c|c|}
\hline Baseline characteristic of diabetic patients $(n=236)$ & $\begin{array}{l}\text { Diabetes at diagnosis } \\
\qquad(\mathrm{n}=179)\end{array}$ & $\begin{array}{l}\text { On-treatment diabetes } \\
\qquad(\mathrm{n}=57)\end{array}$ & $P$ value \\
\hline Median age (range), $y$ & $62(25-81) 1$ missing & $54(35-77) 0$ missing & .02 \\
\hline Male & $102(57)$ & $37(65)$ & .29 \\
\hline Female & $77(43)$ & $20(35)$ & \\
\hline \multicolumn{4}{|l|}{ WHO performance status, $\mathrm{n}(\%)$} \\
\hline 2 & $11(6)$ & $4(7)$ & \\
\hline 3 & $1(1)$ & 01 missing & \\
\hline \multicolumn{4}{|l|}{ Tumor grade, $\mathrm{n}(\%)$} \\
\hline Grade 1 & $54(31)$ & $12(22)$ & \\
\hline Grade 2 & $113(65)$ & $41(75)$ & .41 \\
\hline Grade 3 & 6 (4) 6 missing & 2 (4) 2 missing & \\
\hline Everolimus \pm SSA & $103(58)$ & $35(61 \%$ & \\
\hline SSA & $76(42)$ & $22(39)$ & .61 \\
\hline \multicolumn{4}{|l|}{ Previous treatments, $\mathrm{n}(\%)$} \\
\hline Surgery & $109(61)$ & $34(60)$ & .87 \\
\hline Loco-regional and ablative therapies & $34(19)$ & $19(33)$ & .02 \\
\hline Somatostatin analogs & 96 (54) 2 missing & 35 (62) 1 missing & .28 \\
\hline Chemotherapy & 39 (23) 6 missing & 18 (32) 1 missing & .15 \\
\hline PRRT & $40(22)$ & $15(26)$ & .54 \\
\hline \multicolumn{4}{|l|}{ Time from initial diagnosis to everolimus or SSA treatment } \\
\hline$\leq 6 \mathrm{mo}$ & $65(37)$ & $18(32)$ & \\
\hline$>6 \mathrm{mo}$ to $\leq 2 \mathrm{y}$ & $38(21)$ & $19(33)$ & .35 \\
\hline$>2 y$ to $5 y$ & $33(19)$ & $9(16)$ & \\
\hline Lung & $14(8)$ & $7(12)$ & .30 \\
\hline Bone & $23(13)$ & $11(19)$ & .23 \\
\hline Peritoneum & $23(13)$ & $5(9)$ & .41 \\
\hline $\mathrm{BMI}, \mathrm{kg} / \mathrm{m}^{2}$, median (range) & $24.2(16.6-40.3) 65$ missing & $25.0(18.0-35.3) 10$ missing & .26 \\
\hline
\end{tabular}

BMI, body mass index; PRRT, peptide receptor radionuclide therapy. 
Supplementary Table 4. Characteristics of Diabetic Patients According to Antidiabetic Treatment

\begin{tabular}{|c|c|c|c|}
\hline Baseline characteristic of diabetic patients $(n=236)$ & No metformin (124) & Metformin (112) & $P$ value \\
\hline Median age (range), $y$ & $61(27-80)$ & 60 (25-81) 1 missing & .23 \\
\hline \multicolumn{4}{|l|}{ Sex, n (\%) } \\
\hline Male & $72(58)$ & $67(60)$ & .78 \\
\hline Female & $52(42)$ & $45(40)$ & \\
\hline \multicolumn{4}{|l|}{ WHO performance status, $\mathrm{n}(\%)$} \\
\hline 0 & $86(70)$ & $75(67)$ & \\
\hline 1 & $27(22)$ & $31(28)$ & .55 \\
\hline 2 & $9(7)$ & $6(5)$ & \\
\hline 3 & 1 (1) 1 missing & 0 & \\
\hline \multicolumn{4}{|l|}{ Tumor grade, $\mathrm{n}(\%)$} \\
\hline Grade 1 & $40(33)$ & $26(24)$ & .27 \\
\hline Grade 2 & $77(64)$ & $79(72)$ & \\
\hline Grade 3 & 4 (3) 3 missing & 4 (4) 3 missing & \\
\hline \multicolumn{4}{|l|}{ Previous treatments, $\mathrm{n}(\%)$} \\
\hline Surgery & $73(59)$ & $70(62)$ & .57 \\
\hline Loco-regional and ablative therapies & $32(26)$ & 21 (19) & .19 \\
\hline Somatostatin analogs & 69 (57) 3 missing & $62(55)$ & .80 \\
\hline Chemotherapy & 27 (23) 6 missing & 30 (27) 1 missing & .47 \\
\hline PRRT & $32(26)$ & $23(21)$ & .34 \\
\hline \multicolumn{4}{|l|}{ Metastasis, n (\%) } \\
\hline Liver & $113(91)$ & $92(82)$ & .04 \\
\hline Nodes & 52 (43) 2 missing & $63(56)$ & .04 \\
\hline Lung & $10(8)$ & $11(10)$ & .64 \\
\hline Bone & $17(14)$ & $17(15)$ & .75 \\
\hline Peritoneum & $20(16)$ & $8(7)$ & .03 \\
\hline \multicolumn{4}{|l|}{ Hypoglycemic treatments, n (\%) } \\
\hline Insulin alone & $91(73)$ & - & Not applicable \\
\hline Metformin alone & - & $69(62)$ & \\
\hline Metformin + insulin & - & $31(28)$ & \\
\hline Metformin + GLP1 analogs and DPP-4 inhibitors & - & $12(11)$ & \\
\hline Diet & $33(27)$ & - & \\
\hline Glycemia level, $m g / d L$, median (range) & $164(102-330)$ & $156(100-339)$ & .16 \\
\hline Basal diabetes, n (\%) & $99(80)$ & $80(71 \%$ & \\
\hline Secondary diabetes on-treatment related to adverse events, $\mathrm{n}(\%)$ & $25(20)$ & $32(29)$ & .13 \\
\hline Duration of diabetes, mo, median (range) & $29(0-480) 49$ missing & $24(0-192) 37$ missing & .60 \\
\hline HBA1c, median (range) & $7(5-10) 75$ missing & 7 (4-9) 60 missing & .76 \\
\hline BMI, $\mathrm{kg} / \mathrm{m}^{2}$, median (range) & 24.7 (17.0-40.3) 47 missing & $24.0(16.7-37.5) 28$ missing & .69 \\
\hline
\end{tabular}

BMI, body mass index; DDP4, Dipeptidyl peptidase-4 inhibitor; GLP1, Glucagon-like peptide 1; HBA1c, glycosylated hemoglobin; PRRT, peptide receptor radionuclide therapy; WHO, World Health Organization.

Supplementary Table 5. Results of the Multivariable Analysis for PFS in Diabetic Patients

\begin{tabular}{lllc}
\hline \multicolumn{1}{c}{ Covariate } & \multicolumn{1}{c}{ Subgroups } & HR $(95 \% \mathrm{Cl})$ & $P$ value \\
\hline Age, $y$ & Pemale vs male & $1.03(0.69-1.52)$ & .89 \\
Sex & Metformin vs no & $0.46(0.29-0.72)$ & .001 \\
Metformin & Insulin vs no & $0.87(0.56-1.33)$ & .51 \\
Insulin & G3 vs G1 or G2 & $6.44(2.44-16.98)$ & $<.0001$ \\
Grading & Yes vs no & $0.81(0.55-1.19)$ & .29 \\
Primary tumor $\quad$ resection & & & \\
$\quad$ Liver metastases & Yes vs no & $1.25(0.61-2.57)$ & .54 \\
Node metastases & Yes vs no & $0.68(0.46-0.99)$ & .04 \\
Peritoneal metastases & Yes vs no & $0.53(0.27-1.03)$ & .06 \\
& & & \\
\hline
\end{tabular}


Supplementary Table 6. Sensitivity Analysis: PFS in the Subgroup of Patients Who Presented With Diabetes at Diagnosis (Diabetes at Baseline)

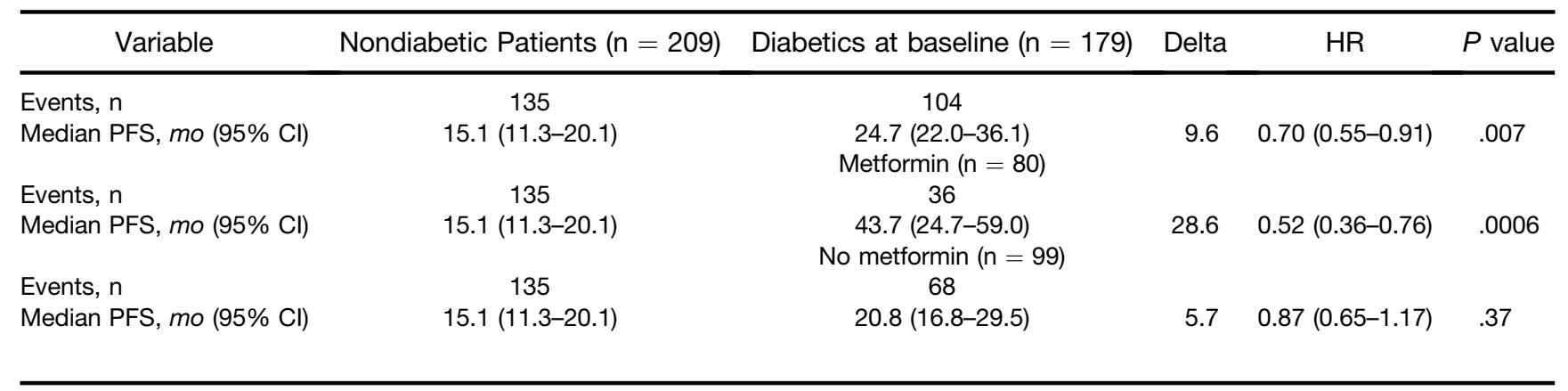

Supplementary Table 7.Landmark Analysis: PFS in Patients Who Started Metformin Before or Within 3 Months From Treatment Initiation Compared With Patients Who Never Took Metformin or Who Started It Later

\begin{tabular}{|c|c|c|c|c|c|}
\hline Variable & $\begin{array}{l}\text { Patients Receiving Metformin } \\
3 \text { mo After the start of } \\
\text { Treatment }^{a}(n=65)\end{array}$ & $\begin{array}{c}\text { Patients Not Receiving } \\
\text { Metformin } 3 \text { mo After the Start } \\
\text { of Treatment }(n=341)\end{array}$ & Delta & HR & $P$ value \\
\hline Median PFS, mo, $(95 \% \mathrm{Cl})$ & $\begin{array}{l}43.7(33.9-53.5) \\
\text { Patients Receiving MET } 3 \text { mo } \\
\text { After the Start of Everolimus } \pm \\
\operatorname{SSA}^{a}(\mathrm{n}=43)\end{array}$ & $\begin{array}{l}23.3(18.7-27.9) \\
\text { Patients Not Receiving MET } 3 \text { mo } \\
\text { After the Start of Everolimus } \pm \\
\text { SSA }(n=184)\end{array}$ & 20.4 & $0.64(0.43-0.93)$ & .02 \\
\hline Median PFS months $(95 \% \mathrm{Cl})$ & $\begin{array}{l}36.1(18.2-53.9) \\
\text { Patients Receiving Metformin } 3 \\
\text { mo After the Start of SSA } \\
\text { Alone }^{a}(n=22)\end{array}$ & $\begin{array}{l}16.7(13.8-19.6) \\
\text { Patients Not Receiving Metformin } \\
3 \text { mo After the Start of SSA } \\
\text { Alone }(n=157)\end{array}$ & 19.4 & $0.67(0.43-1.04)$ & .07 \\
\hline Events, n (\%) & $6(27.3)$ & $86(54.8)$ & & & \\
\hline Median PFS months $(95 \% \mathrm{Cl})$ & Not reached & $32.6(26.1-39.2)$ & NA & $0.42(0.18-0.96)$ & .04 \\
\hline
\end{tabular}

NA, not applicable.

${ }^{b}$ Including patients who never received metformin and patients who started metformin more than 3 months after therapy initiation.

${ }^{a}$ Including both patients who already received metformin at baseline and patients who developed early hyperglycemia after the start of treatment. 
Supplementary Table 8.PFS in Subgroup of Patients Receiving Everolimus Alone

\begin{tabular}{|c|c|c|c|c|c|}
\hline Variable & $\begin{array}{l}\text { Nondiabetic patients } \\
\qquad(\mathrm{n}=20)\end{array}$ & Diabetics $(n=17)$ & Delta & $\mathrm{HR}$ & $P$ value \\
\hline $\begin{array}{r}\text { Median PFS, mo, }(95 \% \mathrm{Cl}) \\
\text { Everolimus without SSA }\end{array}$ & $20.1(4.4-35.8)$ & $\begin{array}{c}24.7(9.5-39.8) \\
\text { Diabetics receiving } \\
\text { metformin }(n=9)\end{array}$ & 4.6 & $0.70(0.28-1.75)$ & .45 \\
\hline $\begin{array}{r}\text { Median PFS, mo, (95\% Cl) } \\
\text { Everolimus without SSA }\end{array}$ & $20.1(4.4-35.8)$ & $\begin{array}{l}\text { NR }(\mathrm{NR}-\mathrm{NR}) \\
\text { Diabetics not receiving } \\
\text { metformin }(\mathrm{n}=8)\end{array}$ & NA & $0.28(0.06-1.27)$ & .10 \\
\hline $\begin{array}{r}\text { Median PFS, mo, }(95 \% \mathrm{Cl}) \\
\text { Everolimus without SSA }\end{array}$ & $20.1(4.4-35.8)$ & $13.0(11.5-14.4)$ & -7.1 & $1.80(0.62-5.20)$ & .28 \\
\hline
\end{tabular}

NA, not available; NR, not reached. 